Wolfgang Grünstäudl

\title{
Petrus Alexandrinus
}

\section{Studien zum historischen und theologischen Ort des Zweiten Petrusbriefes}

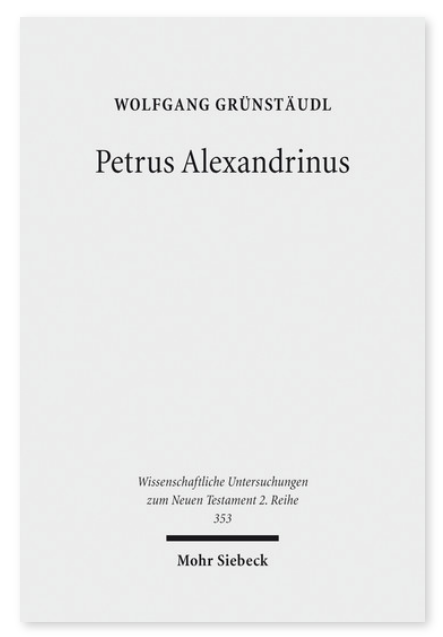

2013. XII, 363 Seiten. WUNT II 353

ISBN 978-3-16-152442-4

DOI 10.1628/978-3-16-152442-4

eBook PDF 104,00€

ISBN 978-3-16-152440-0

fadengeheftete Broschur 104,00€
2Petr, dessen Existenz erst von Origenes zweifelsfrei bezeugt wird, gilt aufgrund seines scheinbar kaum näher bestimmbaren historischen Kontextes in der neutestamentlichen Exegese als »text without a home« (Michael Gilmour). Durch die intensive Analyse der Beziehungen des 2Petr zu anderen petrinischen Pseudepigraphen des frühen Christentums und die umfassende Überprüfung (möglicher) früher Spuren einer Rezeption dieses Briefes gelangt Wolfgang Grünstäudl zu der These, 2Petr sei als Text des alexandrinischen Christentums in der zweiten Hälfte des zweiten Jahrhunderts entstanden. Für die weitere exegetische Arbeit am 2Petr sind dabei vor allem die Nachweise einer literarischen Abhängigkeit des 2Petr von der griechischäthiopischen Petrusapokalypse und der theologischen Nähe zum Umfeld des Clemens von Alexandrien von besonderer Bedeutung.

Ausgezeichnet mit dem Manfred Lautenschlaeger Award for Theological Promise 2014, dem Armin Schmitt Preis für biblische Textforschung und dem Kardinal-Innitzer-Förderungspreis.

Wolfgang Grünstäudl Geboren 1977; Studium der Kath. Fachtheologie und der Kath. Religionspädagogik; 2013 Promotion; 2013-18 Akademischer Rat, seit 2018 Akademischer Oberrat am Institut für Kath. Theologie der Bergischen Universität Wuppertal.

https://orcid.org/0000-0001-8720-2972

Jetzt bestellen:

https://mohrsiebeck.com/buch/petrus-alexandrinus-9783161524424?no_cache=1

order@mohrsiebeck.com

Telefon: +49 (0)7071-923-17

Telefax: +49 (0)7071-51104 